\section{HOW FAR CAN THE ABUSE OF DRUGS BE PREVENTED BY LAW ? 1}

BY WIPPEIL GADD,

OF THE MIDDLE TEMPLE AND WESTERN CLRCUIT, BARRISTER-AT-I.AW.

IT is not my purpose to-night to try to prove by the presentation of facts and figures that drugs are abused to an extent almost commensurate with that of their legitimate and profitable use. That I think may be taken as a fact patent to all who have had any opportunity of studying the subject. My object is rather to touch briefly upon the present state of the law in regard to such matters, to indicate how far it deals with them $(a)$ theoretically and $(b)$ effectively, to consider to what extent it needs strengthening, and in that connexion to refer to laws raling in other lands and in our own colonies, with the object of suggesting how far we may, with different traditions, methods of life, and habits of thought, adapt to our own use such of them as appear to be wise and practicable.

It is desirable in the first place to define one's terms. What is a drug? By the Sale of Food and Drugs Act, 1875, section 2 (38 and 39 Vict. c. 63 ), it was enacted that "the term Drug shall include medicines for internal or external use." Now the function of a medicine is, I take it, to correct irregularities caused by disease, and in so far as it is useful for that purpose it is pro tanto inimical to normal healthy life. All medicines, that is to say, all drugs, are therefore in a sense poisons, but obviously there is a wide range to their respective toxic powers, and in speaking of the abuse of drugs I shall confine myself to those which are more actirely poisonous, although by no means only to those which are scheduled legally as poisons in the Pharmacy Acts. The subject of the abuse of drugs may be divided as follows. 1. Criminal and vicious abuse. 2. Abuses caused by the administration of drugs ostensibly for the relief of suffering and the cure of disease by persons who are not competent to judge of their suitability for particular cases. This may be subdivided into: $(a)$ the prescribing of medicine by un qualified persons to sufferers for gain; $(b)$ the offering broadcast of reputed remedies for specific complaints-i.e., the sale of nostrums and patent medicines; $(0)$ the sale and administration of drugs for complaints which have been self-diagnosed; and $(d)$ the unauthorised use of medicines originally prescribed by a duly qualified medical practitioner for a particular patient in a specific state at a certain time.

1. Criminal and vioious abuse. - The criminal abuse of drugs is but little restrained by English law. Legislation has been aimed apparently rather at punishing offenders than at preventing offences. By the offences against the Person Act, 1861 (24 \& 25 Vict. c. 100), it was made a felony for any person (a) to administer to, or cause to be administered to, or to be taken by, any person any poison or other destructive thing with intent to commit murder or to attempt to do any of these things; $(b)$ to apply or administer to or cause to be taken by or attempt to apply or administer to, or attempt to cause to be administered to or taken by, any person, any chloroform, laudanum, or other stupefying or overpowering drug, matter, or thing, with intent in any of such cases thereby to enable himself or any other person to commit or with intent in any such cases thereby to assist any other person in committing any indictable offence; (c) to anlawfully and maliciously administer to or cause to be administered to, or taken by any other person, any poison or other destructive or vicious thing so as thereby to endanger the life of such person, or so as thereby to inflict upon any person any grievous bodily harm ; (d) to unlawfully and maliciously send or deliver to or cause to be taken or received by any person any dangerous or noxious thing with intent to do some grievous bodily harm; and $(e)$ for a woman, being with child, with intent to procure her own miscarriage, to unlawfully administer to herself any poison or other noxious thing, and for any one with intent to procure the miscarriage of any woman, whether she be or be not with child, to unlawfully administer to her or cause to be taken by her any poison or other noxious thing; and a misdemeanour to (i) unlawfully and maliciously administer to, or cause to be administered to, or taken by, any other person,

1 A paper read before the Medico-Legal Society on March 21st, 1911. any poison or other destructive or noxious thing with intent to injure, aggrieve, or annoy such person; or (ii) to un lawfully supply or procure any poison or other noxious thing knowing that the same is intended to be unlawfully used or employed with intent to procure the miscarriage of any woman, whether she be or be not with child.

The question as to what is a poison or noxious thing was discussed in R. $v$. Cramp (1880), 5 Q B.D. 307, some earlier cases, R. v. Perry (1847), 2 Cox 223; R. v. Isaacs (1862), 9 Cox 228: and $\mathrm{R}, v$. Hennah (1877), 13 Cox 547, being considered and reviewed. It would seem that the question is one of fact, it being essential to show that the substance was noxious in the amount used in any particular case. In none of these cases is there any prohibition of the sale of poisons or noxious substances by persons having no guilty knowledge of the unlawful purposes for which they are procured Indeed, I know of but one English Act which prohibits the sale of poisons-viz., The Poisoned Grain Prohibition Act 1863 (26 and 27 Vict., c. 113), by Section 2 of which it was enacted that -

Every person who shall offer or expose for sale or sell any grain, seed, or meal which has been so steeped or dipped in poison, or with whic any poison or any ingredient or preparation has been so mixed, as thereby to render the same poisonous and calculated to destruy life, hall in either case for every such offence upon summary conviction, a hereinafter provided, forfeit any sum not exceeding ten pounds.

I do not forget the Arsenic Act or the Pharmacy Acts of 1868 and 1908 , but they allow even scheduled poisons to be sold to anyone known to the seller after due performance of certain rites and ceremonies connected with the Poisons Register which sellers have to keep. Far be it from me to doubt the usefulness of the Poisons Register; it is the opinion of those qualified to judge that even in the case of intended suicides the difficalties placed in the way of the person seek. ing to obtain the poison often sufficiently disgust him to turn what is probably the ill-defined purpose of an unbalanced mind. In the case of intended murder the Poison Register is not likely to act as a deterrent, its chief use being as an aid to subsequent detection and conviction.

With regard to accidental poisoning, the difficulties of obtaining an article, accompanied as such sales very often are with words of advice and warning from the specially qualified person who can alone sell scheduled poisons by retail, often effectually impress the purchaser with the dangerous nature of the substance which he proposes to use and thus mishaps are prevented. But the weakness of the existing schedale is its want of elasticity. It contains only certain definitely named substances and classes of substances. Whilst expressly including all poisonous vegetable alkaloids it does not embrace synthetic substitutes for alkaloids of equal or greater potency, as, for example, eucaine, novocain, and stovaine. Again, whereas sulphonal is specifically included, similar hypnotics, such as veronal, trional, \&c., are outside the schedule. It is true that there is power given to the Prizy Council, acting at the suggestion of the Pharmaceutical Society, to add from time to time to the schedule, but there seems a strange reluctance on the part of the Privy Council to exercise this power. For example, in spite of the fact that representations have been repeatedly made concerning the use of diachylon (lead plaster) as an abortifacient, the Privy Council has declined to put it upon the schedule. Phosphorus has been the cause of many deaths, but the one answer to representations that it should be put on the schedule appears to be "matches"-a consideration of domestic convenience which has lost what little force it ever had by the prohibition of manufacturing, selling, and importing matches made with white phosphorus by the White Phosphorus Act, 1908 (8 Ed. VII., Chapter 42), which came into force on Jan. 1st, 1910.

I believe that in other countries, and in some of the American States, there is more elasticity in such schedules thus, speaking from memory, the Poison Schedule of the State of Michigan, U.S.A., contains a provision to the effect that any drugs, the medicinal dose of which, as stated by medical authorities, is not more than some few grains, becomes ipso faoto a scheduled poison Nor is this a new idea, for as Jong ago as 1682 Louis XIV. of France issued a decree forbidding apotbecaries to sell "arsenic, sublimate, or any drug reputed to be a poison, except to persons known to them,. who should sign the register declaring the purpose for which they were buying the poison."

I submit that an addition might well be made to the English Schedule to the effect that any drag, the maximum 
medicinal dose of which is stated by the makers thereof, or by competent medical authorities, not to exceed two grains for an adult, should be considered a poison within the meaning of the Pharmacy Acts. But the schedule is practically useless as a means of restraining the vicious abuse of drugs, that is to say, their excessive use by victims of drug babits. For such, in most civilised countries, and particularly in the United States of America, there are prohibitive laws.

The time at my disposal in preparing this paper and the difficulty of access to primary sources of information prevent my giving you a summary of these; but some examples, taken almost at random may suffice to illustrate the point. Thus in 1910 a French pharmacist was fined $£ 40$ for delivering morphine without a regular prescription. In 1908 a Berlin druggist was fined $£ 25$ with the option of 50 days' imprisonment for selling morphine to a lady, in addition to being sned by her husband for damages. In the Chomist and Druggist of Nov. 27th, 1909, it was stated that-

The laws restricting the sale of narcotics are becoming more and more severe in the United States. It has been customary to make sales by pharmacists only on physicians prescriptions, but now a lowa statuly porbics tho dispenging or prescriptions unless they aro presented in person by the physician who wrote them, and unless the physician also signs the poison register.

In Germany the repetition of prescriptions for internal use containing chloral hydrate, chloral formamide, morphine, heroin, cocaine or their salts, preparations of ethylene, amylene hydrate, paraldehyde, sulphonal, trional, urethan, or veronal, is forbidden unless the prescriptions bear the date and the renewed signature of a qualified medical practitioner. In Austria it is forbidden to dispense any prescriptions which are copies of original prescriptions. In Hungary, in the case of potent drugs, distinguished in the Pharmacopœia by having two crosses against the title, a new prescription calling for one of these as an ingredient must be written out for each supply, and such prescriptions must be made up within 48 hours in places provided with a pharmacy, other. wise within four days. In Norway pharmacists are forbidden to supply certain powerful drugs except on the prescription of authorised medical practitioners, a list of whom has to be kept in every pharmacy. Similar rules exist in Russia.

In the British dominions only the legislature of Alberta controls the sacred right of British subjects to obtain what poison they wish, and that only since Dec. 16th last, when a new Pharmacy Act became law, enacting, inter alia, that no one may sell by retail the alkaloid cocaine or its salts, alph or beta cocaine or their salts, or any admixture of cocaine or encaine except upon the written prescription of a legally qualified medical practitioner. The prescription is to be retained by the retailer and not filled more than once, and no copy may be given.

In the case of scheduled poisons the fact that their sale is restricted to qualified pharmacists is, of course, a great safeguard. Pharmacists are by their training and experience essentially cautious, and the standard of education, intelligence, and high principle amongst them was never so high as it is to-day. But to distinguish purchasers of drugs for legitimate uses from those who seek them for illicit ends is always invidious and of ten impossible, and the authorised dealers would doubtless welcome legal restrictions which wonld enable them to take up a non possumus attitude.

$2(a)$. Unqualified presoribing. - The only statute directly restricting unqualified practice in this country is the Apothecaries Act, 1815 (55 Geo. III., c. 194), Section 20 of which probibits persons who are not legally qualified as medical practitioners from acting or practising as apothecaries. What is acting as an apothecary is not defined, but has been considered in a series of cases. The element of doubt is chiefly in regard to what is sometimes called counter-prescribing by pharmacists. If an examination of the patient be made, followed by the prescribing and supplying of a remedy, there would seem to be no doubt that a technical offence at least is committed. but it is not so clear whether suggesting a remedy for a self-diagnosed complaint is acting as an apothecary. If it be so, it is doubtful whether it would be good public policy to strictly enforce the Act. "The best," said a wise man, " is the enemy of the good," and counsels of perfection have sometimes strange results when applied to faulty human affairs.

Under present conditions the alternative to seeking the advice of a vendor of repute with a character to lose is usually the swallowing of both the advice and the nostrum of an anonymous medicine-monger, probably resident on the other side of the Atlantic, and certainly immune to any form of moral suasion. For the quack blatant there should be no consideration; for his case the prescription contained in the Penal Oode of Brazil, combining as it does pecuniary penalties with opportunities for reflection, would seem well suited :-

For exercising medicine in any of its branches, dentistry or pharmacy ; for practising homæopathy, midwifery, and hypnotism or animal magnetism, without being licensed according to the laws and regulations:- Peralty: Solitary confinement for one to six months and a fine of 100,000 reis to 500,000 reis.

$2(b)$. Briefly I would submit some considerations concerning the sale of nostrums and patent medicines. Here again it is not necessary to present the facts, he who runs must read, and if he takes refuge in a railway train, too often the cinematic landscape which unfolds before him makes the same appeal to his valetudinarian fancies and morbid anxieties as to his physical well-being.

The law allows anyone to manufacture and put up for sale medicines for human use, and to label them with such fantastic virtues as a vivid imagination may suggest, provided only that if in the exuberance of his verbosity the proprietor claims either that his preparation will cure disease or that he and he alone knoweth the secret of its composition, he is taxed to the extent of some $12 \frac{1}{2}$ per cent. of the value he puts upon his remedy, with the compensating advantage of receiving an official acknowledgment which to the illiterate seems to lend authority to audacity.

For the retailing of stamped medicines a licence is required, but seeing that such can be obtained for 58. per annum, there is practically no restraint on the vending of them.

Proprietary articles containing scheduled poisons are subject to the provisions of the Pharmacy Acts (vide Pharmaceutical Society $v$. Piper, (1893) 1 Q. B. 686). Pharmaceutical Society v. Armson, (1894) 2 Q. B. 720), Very few proprietary articles are the subjects of letters patent, the Pharmaceutical Society having on many occasions secured the revocation of patents for medicines containing scheduled poisons, great weight being paid by the Chancery courts to the argument that the effect of the patent would be to enable the patentee to sell without restriction an article which, if not protected by letters patent, could not thus be sold.

Stamp duties on medicines are governed by the Acts 42 Geo. III., c. 56 ; 44 Geo. III., c. 98 ; and 52 Geo. III., c. 150 . The exemptions are as follows :-

1. All medicinal drugs whatsoever, whether recommended or not, which shall be uttered or vended entire without any mixture or composition with any other drags or ingredients (52 Geo. III., c. 150). Such substances are only exempt from liability to stamp duty when sold by a chemist and druggist, surgeon, or apothecary, or by a person holding a patent medicine licence. Other persons selling entire drugs unstamped are not entitled to this exemption.

2. Ginger and peppermint lozenges or any other article of confectionery, unless the person vending the same shall vend them as medicines or as beneficial for the prevention, cure, or relief of any distemper, or ailment, or disorder incident to or in any wise affecting the human body (55 Geo. III., c. 184).

3. All artificial mineral waters and all waters manufactured with soda or mineral alkali or with carbonic acid gas and all compositions in a liquid or solid state to be used for the pur. pose of compounding or making any of the said waters ( 3 \& 4 Will. IV., c. 97).

4. Preparations known, admitted, and approved of as remedies when sold by chemists and druggists, surgeons, on apothecaries, provided always that the rendor does not (a) claim or possess any occult secret or art in mixing the preparation; $(b)$ claim or possess any exclusive proprietorship; (c) issue the preparation under letters patent; or (d) recommend the preparation as a nostrum or specific.

It is the last of these exemptions to which I wish to direct your attention. For many years it remained a dead letter until the question of its applicability was raised in the case of Farmer $v$. Glyn-Jones, which was decided in favour of the defendant both by the magistrate and on appeal (1903 K. B. 2, p. 6). Following on this decision the Board of Customs and Excise has laid down the following main lines upon which to base its procedure: A preparation is regarded as known, admitted, and approved (1) if the label bears a 
statement of the ingredients of the medicine or adequate Indication of the active ingredients; or (2) if the medioine is prepared according to some well-known book of formulæ and the name of such book or initials denoting it, followed by a number for the ready identification of the particular $f$ rmula, are stated or indicated on the label The onus of proving that the composition of a preparation sold accords with the assertion made or implied on the label rests with the vendor who claims the exemption. Since this decision it has been the practice of pharmacists to sell remedies for specific complaints without stamps under cover of this exemption, the active ingredients being indicated on the label or the source of the formula denoted by initials or numbers.

Is it not possible that in some amendment or rather exten. gion of this practice there may be found the germ of a possible solution of the vexed question of proprietary articles and secret remedies ? It is futile to ask, in the present state of public opinion, even if it be desirable, for prohibitive or drasticaliy restrictive legislation. The British public dearly loves cure-alls exhibited in bottles. The spread of education which it might have been hoped would have cured this propensity seems but to have provided further avenues for advertising exploits and the means of reaching a wider public as willing to be gulled as their more illiterate forbears. Sensational exposures are soon forgotten, especially if they come from an apparently interested qnarter.

The recent work published by the British Medical Association on "Secret Remedies," althnugh armirably conceived, is, I would submit with great respect, imperfectly carried out. Too much stress is laid upon the bare cost of the alleged ingredients of the nostrums dealt with. To a sick man seeking health it matters but little whether he who brings him relief finds a substantial pecuniary recompense for doing so or not. Moreover, the difficulty attendant on the exact analysis of organic vegetable mixtures makes it easy for the manufacturer to repudiate as incorrect a cormula based on the work of the analyst alone. But why should not the onus be laid on all manufacturers putting forth claims to cure disease of stating the composition or at least the active ingredients of their preparations in some such way as is already done by those who seek to evade the meidence of the Stamp Daty? Such manufacturers would still retain their common law rights as regards protection against passing off-that is to say, other traders, although they might be able to make preparations from the same formula, would be restrained from any action which would deceive purchasers into thinking that they were obtaining an article actually made by the original introducer. Medicines for which a genuine originality could be claimed might, of course, be made the subject of letters patent.

I am quite aware that legislation on such lines would be strennously opposed, but is it not called for in the interests of public health and morality, and is it beyond the wit of Parliamentary draughtsmen to frame some Bill which would protect the public without doing serious injury to interests which have become vested by long user?

In cases in which absolutely false statements are made legislation should proceed on more drastic lines. In this connexion we may usefully imitate the Quackery Prevention Act, 1908, of New Zealand, the operative clauses of which are as follows :-

2. Every person commits an offence who publishes or causes to be oublished any statement which is intended by the defendant or any other person to promote the sale of anv article as a medicine, preparation, or appliance for the prevention, alleviation, or cure of any human tion, or appliance for the prevention. alleviation, or cure of any himan ailment or physical defect, and which is false in any material particular relating to the ingrenients, composition, structure, nature, or operation of that article, or to the effects which have followed or may follow the use thereof.

3. A statement shall be deemed to be published within the meaning of this Act if it is inserted in any newspaper printed and published in New Zealand, or is publicly exbibited in view of persons in any road, atreet, or other public place, or is contained in any document which is gratuitously sent to any person through the post office or otherwise, or which is gratuitously delivered to any person or left upon premises in be occupation of any person.

4. Every person who commits an offence against this Act is liable, on summary conviction before a magistrate, to a fine not exceeding on hundred pounds in the case of a first conviction for any suih offence, and not exceeding two hundred pounds in the case of a second or any subsequent ennviction.

5. It any person causes anv statement to be inserted in breach of this Act in a newspaper printed and publisher in New /ealand, the printer publisher, and proprietor of that newspaper shall severally (and without axcluding the liability of any other person) be deemed to have publisher that statement in breach of this Act, and shall be liable for an offence agairst this Act accuraing!y. 2(c). The sale and admenistration of drugs for oomplaints whioh have been self-diagnosed.-A modern ill of rapidly increasing virulence is the habit of persons, often of good general education, but with little or no scientific, still less medical, training, purchasing and taking potent drugs for morbid conditions, real or imaginary, from which they are suffering or suppose themselves to be suffering.

The practically unrestrained access to hypnotics and analgesics and other potent medicaments fosters this abuse, although not often to so rapidly fatal an end as in the recent case of a member of the legal profession in Cornwall, who is alleged to have had a vivid appreciation of the convenience of medicines hammered into small bi-convex shapes and an absolute ignorance that corrosive sublimate in this form was not meant for internal consumption.

Here I can but reiterate my plea for the extension of the poisons schedule, so that it may include all powerful drugs, but apart from legislative action, could not medical men be induced to revert to the good old custom of prescribing in full Latin and technical terms rather than by popularly understood and readily recognised synonyms, the latter practice being calculated to fatally familiarise the public with the names of drugs without enlightening them as to their toxic power?

Lastly and britfly, the abuse of drugs by the unauthorised use of medicines originally prescribed by duly qualified medical practitioners for a particular patient in a specific state at a certain time. The question of the repeated dispensing of medical prescriptions which are often used long after their original purpose has been served, handed to friends, and perchance, if nanseous, to enemies, and even treated as heirlooms, is one of some difficulty. The whole question of the ownership of such prescriptions was discussed at length in THE LANCET of Oct. 1st, 15th, and 22nd, and Nov. 12th of last year, the conclusion arrived at being that the prescription was the property of the patient who had received it in return for a fee, and that the only restraint on its undue repetition was by an honourable understanding between physicians and pharmacists, any breach of which should be treated rather as a violation of professional etiquette than as a legal offence.

It would be impossible for me to acknowledge all the sources of information which $I$ have used in preparing this paper, but I must mention the Pliarmaceutioal Journal, $\mathrm{Mr}$. Glyn-Jones's work on the " Law of Poisons," and particularly my indebtedness to the editorial staff of the Chemist and Druggist for the trouble they have taken in obtaining, at my request, information concerning the legislation of other countries.

\section{AN UNUSUAL CASE OF BULLET WOUND OF THE SKULL.}

BY W. L. HARNETT, M.B. CaNTaB., F.R.C.S. ENG., CAPTAIN, INDIAN MEDICAL SERVIOE.

Aт Meerut, India, on Feb. 15th, 1910, one of the syces of the 31st (D.C.O.) Lancers was cutting grass in a field situated about one mile behind the rifle range. Musketry practice was going on at the time, and firing was taking place from the 1000 yards firing point. Some other men who were cutting grass in company with him said that they heard a sound of something rushing through the air, and immediately afterwards the man dropped to the ground unconscious and with a wound in his head. As the man was about one mile, or say 1800 yards, behind the butts, and the bullet which struck him was fired from a point 1000 yards in front of the target, he must have been hit from a range of at least 2800 yards, which is the extreme range up to which the new short rifle is sighted.

On admission to hospital the patient was conscious, but soon afterwards he became drowsy and could be roused only with difficulty. The pulse was slow, the pupils were moderately dilated, and the corneal reflex was present. No paralysis was noted at the time. There was an oval wound in the left side of the head about $1 \frac{1}{4}$ in above the upper margin of the ear. The patient was anæsthetised and a flap was turned down including the wound. On clearing the bone an oval opening was found in the left temporal bone about one inch long and three-quarters of an inch broad. It was found possible to remove the comminated bone from 